\title{
DEFESA DO INTERNATO NA INSTRUÇÃO PÚBLICA SECUNDÁRIA PROVINCIAL (SERGIPE/BRASIL, SÉCULO 19)
}

DOI: http://dx.doi.org/10.1590/2236-3459/49774

\author{
Joaquim Tavares da Conceição \\ Universidade Federal de Sergipe, Brasil.
}

$\cos 8$

\begin{abstract}
Resumo
Neste artigo são analisados debates e medidas de autoridades provinciais em torno da utilização do internato em estabelecimentos de instrução pública secundária. Segundo as autoridades, o internato promoveria uma maior demanda aos liceus e possibilitaria que jovens de regiões interioranas pudessem cursar o ensino secundário nos liceus das capitais ou evitaria a saída desses jovens para outras províncias em busca de instrução. As iniciativas de adoção do internato eram propostas com a gratuidade do ensino, mas exigindo o pagamento da pensão referente à cama e à comida. A medida visava a atender, principalmente, aos anseios pelo ensino secundário das elites provinciais, que eram os segmentos que podiam arcar com os custos do internato.

Palavras-chave: internato, instrução secundária, províncias, educação, história.
\end{abstract}

\section{DEFENSE OF PUBLIC EDUCATION IN SECONDARY BOARDING PROVINCIAL (SERGIPE/BRAZIL, 19 CENTURY)}

\begin{abstract}
This article analyzes debates and measures of provincial authorities around the use of boarding establishments in secondary public education. In accordance with authorities, the boarding promote a greater demand for high schools and would allow young people from inland regions can make the secondary studies in high schools of the capital or prevent the release of these young people to other provinces seeking learning. Adoption of initiatives have been proposed internship with free education, but it required the pension payment for bedding and food.The measure was designed to cater primarily to the yearnings for secondary education of provincial elites who were the segments that could afford the costs of boarding.

Key-words: boarding school, secondary education, provinces, education, history.
\end{abstract}

\section{DEFENSA DEL INTERNADO EN LA INSTRUCCIÓN PÚBLICA SECUNDARIA PROVINCIAL (SERGIPE/BRASIL, SIGLO 19)}

Resumen

Este artículo analiza debates y medidas de autoridades provinciales alrededor de la utilización del internado en establecimientos de instrucción pública secundaria. Según las autoridades, el 
internado promovería una mayor demanda de los liceos y posibilitaría que jóvenes de regiones del interior pudieran cursar la enseñanza secundaria en los liceos de las capitales o evitaría la salida de esos jóvenes para otras provincias en busca de instrucción. Las iniciativas de adopción del internado eran propuestas con la gratuidad de la enseñanza, pero exigiendo el pago de la pensión referente a dormitorio y comida. La medida pretendía atender, principalmente, el anhelo por la enseñanza secundaria de las élites provinciales, que eran los segmentos que podían enfrentar los costos del internado.

Palabras-clave: internado, instrucción secundaria, provincias, educación, historia.

\section{LA DÉFENSE DE L'INTERNAT DANS L'INTRUCTION PUBLIQUE SECONDAIRE PROVINCIAL (SERGIPE/BRÉSIL, $19^{\mathrm{e}}$ SIĖCLE)}

\section{Résumé}

Cet article analyse les débats et mesures des autorités provinciales autour de l'utilisation des internats de l'enseignement public secondaire. D'après les autorités, l'internat promouvrait-il une augmentation de la demande des écoles secondaires et permettrait aux jeunes de la régions de l'intérieur faire les études secondaire aux Lycées de la capitale ou empêcherait la sortie de ces jeunes à d'autres provinces à chercher de l' instruction. Les initiatives d'adoption de l'internat ont été proposées avec la gratuité de l'éducation, mais il exigeait le paiement d'une pension pour la literie et la nourriture. La mesure avait le but de répondre principalement aux aspirations de l'enseignement secondaire des élites provinciales qui ont été les segments qui pouvaient prendre en charge les coûts de l'internat.

Mots-clé: l'internat, l'enseignement secondaire, les provinces, l'éducation, l'histoire. 


\section{O internato em debate}

S internatos, ao longo do século 19, apesar das críticas recebidas, subsistiram na cultura escolar brasileira, utilizados por famílias das camadas ricas e estratos médios da população para promover a instrução de seus filhos. Nos internatos, os estudantes encontravam cama, comida - pensionato - e toda a instrução: aulas, repetições, exercícios suplementares, direção dos estudos. Largamente adotado nos estabelecimentos de instrução particular, o internato também foi pensado e até mesmo adotado, tanto pelo governo central, quanto pelos governos provinciais, em determinados estabelecimentos e graus de ensino.

O internato escolar permaneceu como um tema controverso durante boa parte do século 19, especialmente na sua segunda metade. Não havia consenso sobre os benefícios pedagógicos do internamento. A esse respeito é ilustrativo um trecho da escrita, realista e autobiográfica, de Raul Pompéia em O Ateneu (1888):

Discutiu a questão do internato. Divergia do parecer vulgar, que o condena. É uma organização imperfeita, aprendizagem de corrupção, ocasião de contato com indivíduos de toda origem? O mestre é a tirania, a injustiça, o terror? [...] A reclusão exacerba as tendências ingênitas? Tanto melhor é a escola da sociedade. Ilustrar o espírito é pouco; temperar o caráter é tudo. É preciso que chegue um dia a desilusão do carinho doméstico. [...] O internato é útil; a existência agita-se como a peneira do garimpeiro: o que vale mais e o que vale menos, separam-se. [...] Não é o internato que faz a sociedade; o internato a reflete. A corrupção que ali viceja, vai de fora. Os caracteres que ali triunfam, trazem ao entrar o passaporte do sucesso, como os que se perdem, a marca da condenação. (Pompéia, 2001, p. 144)

Nesse fragmento estão presentes posições sobre o internato bastante recorrentes nos discursos de autoridades da instrução e de intelectuais em boa parte do século 19. A primeira, provavelmente dominante, impingia ao internato um valor negativo por propiciar a degradação física, moral e intelectual de pensionistas de colégios internatos. Essa visão dos internatos pode ser encontrada em teses doutorais defendidas por médicos formados nas Faculdades de Medicina da Bahia e do Rio de Janeiro. Para alguns médicos, interessados no tema higiene dos colégios, somente as exigências da vida social e a necessidade de filhos das províncias procurarem nas capitais meios de instrução poderiam justificar o recurso ao internato, impedindo os meninos de serem educados nos externatos sob a direção da família.

O médico Dr. João da Matta Machado era uma voz bastante contundente nesse sentido. Segundo ele, feliz era o pai que podia livrar seus filhos das "emanações pestíferas destas casas de negócio, que se pavoneiam com o título de estabelecimentos de educação!". Nesse mesmo sentido são as conclusões de outros médicos da Faculdade de Medicina do Rio de Janeiro, a exemplo de Candido Teixeira de Azeredo Coutinho, que julgava a maioria dos internatos como "casas de especulação imoral e perigosa" (Coutinho, 1857). Ainda no século 19 encontramos a desaprovação do internato também em teses de médicos da Faculdade de Medicina da Bahia, a exemplo da dissertação do Dr. Sulpício Germiniano Barroso, que reputava o internamento responsável pelo desenvolvimento de "muitos vícios", especialmente o "onanismo" e a "pederastia" (Barroso, 1853). 
Segundo esses médicos a deterioração da saúde dos pensionistas de colégios era resultante de fatores como a admissão de pensionistas com idade inferior a 10 ou 7 anos de idade, do regramento penoso da vida diária nos internatos, que chegava mesmo a aniquilar as vontades individuais, da uniformização de tratamento, a inadequada divisão do tempo das atividades - estudo, recreação, alimentação, asseio, sono -, caracterizada por longas horas de estudo e tarefas sem o descanso higiênico, a deficiência ou inexistência da educação física, de uma educação moral caracterizada pelo uso da pedagogia do medo e dos castigos físicos e humilhantes que resultavam na formação de indivíduos dissimulados ou conformados. Corroborava com esses fatores, debilitando ainda mais a saúde dos pensionistas, o fato de os colégios estarem localizados em locais insalubres, de grande movimentação, dando lugar à proliferação de doenças, e com uma organização interna marcada pela ocupação excessiva dos dormitórios, deficiências na alimentação, iluminação, ventilação e ausência de instalações sanitárias. Foi também uma característica do discurso médico-higiênico a propaganda, com roupagem científica, de que a vida nos internatos exacerbava ou proliferava as práticas da masturbação e do homossexualismo entre os colegiais (Conceição, 2012).

Outra posição apontava o internato como um recurso importante diante das longas distâncias entre casa e colégio ou da falta de estabelecimentos de ensino em determinadas localidades. Mesmo os críticos contundentes do internato reconheciam que o regime era um mal necessário, cuja erradicação era impossível naquelas condições. Todavia, nos casos de que não se podia prescindir dos internatos, as soluções higiênicas deveriam ser adotadas pelos diretores para diminuir os efeitos negativos à saúde dos pensionistas (Machado, 1875).

Entretanto, também existia quem defendesse o recurso ao internato como um modelo ideal para o pleno desenvolvimento das crianças e adolescentes. Neste caso considerava-se que as adversidades enfrentadas no internato agiriam positivamente para fortalecer o indivíduo a fim de enfrentar os desafios do mundo exterior. Em 1879, discorrendo sobre a educação da mulher, Sanches de Frias questionava se essa devia se dar no externato, no internato ou na família. Posicionava-se favorável à reclusão e regularidade do internato como um recurso conveniente ao adiantamento e à correção dos defeitos de uma menina, pois proporcionava horas regulares para a alimentação, trabalhos escolares e para o descanso higiênico - o recreio. Para ele o regramento da vida diária no internato podia "melhorar, se não curar rapidamente, o que é totalmente impossível, se não houver reclusão e reclusão prolongada e sem intermitências" (Frias, 1880 , p. 54). Ainda, para o autor, na condição de externa, a menina estava sujeita à "constante convivência com os criados, que a acompanham, às chalaças e diálogos picantes dos truões de esquina e à prática das assuadas, jogos e entretenimentos dos garotos" (Frias, 1880, p. 57).

Quando o governo imperial planejou, no ano de 1882, a realização do Congresso de Instrução, o internato figurava entre as questões do programa. O Congresso acabou não ocorrendo e, no seu lugar, foi organizada uma exposição pedagógica e a publicação de memórias e pareceres sabre os vários temas propostos no programa (Congresso da Instrução, 1884). A décima terceira questão, que deveria ter sido discutida pelos congressistas, tratava do regime de internato praticado nas escolas normais e colégios públicos de instrução secundária. Sobre esta questão foram apresentados pareceres 
pelos doutores João Carlos de Oliva Maya, Manoel Antonio Duarte Moreira de Azevedo e pelo barão Homem de Melo. O parecer do dr. João Carlos de Oliva Maya foi favorável à adoção do internato, desde que obedecesse a certas regras e fiscalização do governo:

A educação na família entre nós é, por enquanto, mera aspiração. Os internatos, cujo regime é aplicado com igual vantagem nos colégios e nas escolas normais, preenchem os misteres da educação e instrução, obedecendo porém a certas regras e à vigilância do governo por intermédio de seus delegados. Do progresso da pedagogia depende a solução decisiva em prol do regime dos internatos. (Maia, 1884)

Por sua vez, o dr. Manoel Antonio Duarte Moreira de Azevedo defendia que, diante das condições geográficas do Brasil, ainda não era possível suprimir os internatos. Porém, para o seu funcionamento adequado, os internatos deveriam ser instalados em espaços salubres, afastados dos grandes centros de povoação, em edifícios amplos com espaços livres para a prática de exercícios ginásticos e recreios (Azevedo, 1884). Para ele, seguindo essas orientações, os alunos internos teriam uma instrução com higiene física e moral.

O conselheiro Euzébio de Queiroz Coutinho Mattoso Câmara (1812-1868), inspetor geral da Instrução Primária e Secundária do Município da Corte, defendia, desde o ano de 1856, a criação de internatos com o objetivo de aumentar a demanda nas escolas públicas primárias, localizadas nas freguesias de fora da cidade do Rio de Janeiro Inhaúma, Irajá, Jacarepaguá, Campo Grande, Santa Cruz, Guaratiba, Ilha do Governador e Paquetá -, onde os habitantes estavam espalhados e as distâncias eram longas:

Nas freguesias de fora da cidade [...] onde a população é ainda bastante disseminada, seriam os meninos obrigados a percorrerem grandes distâncias e a sofrerem os rigores das estações, com grande dano de sua saúde, para irem quotidianamente receber na escola as lições do professor. [...] Quer seja porém obstáculo real que cumpre superar, quer seja pretexto a que se socorre a má vontade, que é indispensável destruir, não é menos certo que nas freguesias de fora da cidade são as distâncias uma das causas mais poderosas para a pouca frequência da maior parte das escolas, e as circunstâncias excepcionais dessas localidades estão indicando que o meio mais fácil de remover os inconvenientes que temos assinalado, e tornar mais úteis as escolas públicas, é dar-lhes uma organização também excepcional e mais acomodada às necessidades da população que aí se acha estabelecida. Parece-me que se cada uma dessas escolas constituísse uma espécie de internato, desapareceriam a um tempo as dificuldades que se opõem ao desenvolvimento e progresso da instrução primária. (Câmara, 1856, p. 11)

Para a instalação de internatos primários o conselheiro Eusébio de Queiroz argumentava que não ocorreriam acréscimos de despesas, pois as famílias que não fossem desprovidas de recursos financeiros pagariam uma módica retribuição para o sustento e alimentação dos alunos e igualmente arcariam com as despesas do vestuário. Deste modo, convencido das vantagens do internato, o inspetor geral propôs ao delegado da instrução da freguesia da Ilha do Governador que fizesse uma experiência de internato na escola daquela freguesia. Para dar efetividade ao experimento, o governo nomeou um engenheiro para examinar uma casa na citada freguesia, pertencente ao mosteiro de São 
Bento, a fim de indicar se ela poderia ser reformada para o funcionamento do internato ou quais seriam as despesas para a construção de um novo prédio (Câmara, 1856, p. 11). Todavia, em 1858, o conselheiro Euzébio de Queiroz informou que o projeto de criação de um internato para a instrução primária encontrou dificuldades para a sua execução e não se concretizou (Câmara, 1858).

$\mathrm{Na}$ Corte do Rio de Janeiro funcionava, desde a primeira metade do século 19, o Imperial Colégio de Pedro II, estabelecimento público de instrução secundária com internato. O estabelecimento foi fundado em 1837, data natalícia do imperador D. Pedro II, por decreto (Brasil, 1837) do regente Pedro de Araújo Lima, que converteu o antigo Seminário de São Joaquim em colégio secundário, de acordo com o projeto apresentado pelo ministro Bernardo Pereira de Vasconcelos. Para o funcionamento do Colégio Pedro II, que contava com o mecenato do patrono o imperador D. Pedro II (Chwarcz, 2010), o antigo prédio do Seminário de São Joaquim passou por reformas e adaptações sob a orientação do arquiteto Grandjean de Montigny, "um dos componentes da Missão Francesa atraída ao Rio de Janeiro sob os auspícios de D. João VI pelo conde da Barca para fundação da Escola das Belas Artes" (Doria, 1997). Quanto às condições e modos de funcionamento do Colégio Pedro II foi baixado o regulamento de 1838, que passou por diversas alterações durante o Império e no decorrer da República (Brasil, 1838). A respeito do internato esse regulamento determinava as condições de admissão dos alunos internos, a pensão, o enxoval, o regime disciplinar e a economia interna do estabelecimento.

A partir de 1857 a instituição foi dividida em dois estabelecimentos distintos Externato e Internado do Imperial Colégio Pedro II. O Internato, situado em uma chácara na rua de S. Francisco Xavier, n. 3, no Engenho Velho, e o Externato, na rua Larga de S. Joaquim. Nos dois eram idênticos os cursos, regidos pelo mesmo programa de ensino, diferindo somente quanto às disposições regulamentares, peculiares à natureza de cada um deles. O curso dos estudos era de sete anos, repartidos por dezoito cadeiras a cargo de professores catedráticos e substitutos (Internato, 1885). Os alunos do Colégio Pedro II saíam com o diploma de bacharel em Letras, aptos a ingressar nos cursos superiores. Durante o Império e boa parte da República o estabelecimento serviu de modelo para o ensino secundário em todo o país e para as tentativas de adoção do internato nos estabelecimentos públicos.

No governo central do Império havia quem sugerisse a adoção de colégio internato, a exemplo do Pedro II, em estabelecimentos provinciais de ensino secundário. Nesse sentido, como ressalta José Ricardo Pires de Almeida em Instrução pública no Brasil, publicada em 1889, o conselheiro José Idelfonso de Souza Ramos, em 1862, destacava a importância do internato segundo o modelo francês - instrução, cama, comida, supervisão -, para o desenvolvimento dos liceus provinciais que padeciam com a falta de alunos (Almeida, 2000).

\section{Instrução pública secundária provincial: o internato como solução}

O ensino secundário, na prática, tinha como objetivo preparar os alunos para os exames preparatórios exigidos para o ingresso no ensino superior. Portanto, os planos de estudo das aulas ou dos estabelecimentos de ensino secundário giravam em torno das exigências determinadas nos exames para o ingresso nas Faculdades do Império (Haidar, 
2008). Os exames preparatórios eram prestados nos estabelecimentos de "ensino superior; a partir de 1851, também no Rio de Janeiro, perante a Inspetoria de Instrução Primária e Secundária; e de 1874 em diante, estenderam-se a todas as capitais das Províncias" (Nunes, 1999, p. 71).

Sob o ponto de vista da oferta o pensamento de autoridades da instrução pública era de que, diferentemente da universalização do ensino elementar, o ensino secundário deveria ser centralizado em determinados pontos da província e direcionado às classes dirigentes que seguiriam a formação superior ou o exercício de altos cargos públicos (Rebello, 1861). Sobre esse direcionamento do ensino secundário, o dr. Abílio César Borges, diretor geral de Estudos da Província da Bahia, escrevia, em 1856, que o governo deveria impedir ou dificultar o acesso de indivíduos das classes inferiores, até mesmo à instrução primária média, ou mesmo dificultar que avançassem à instrução secundária. Argumentava o dr. Abílio César Borges que facilitar o acesso à instrução secundária para todas as classes acabaria por criar uma "classe de meios sábios, enfatuados e pedantes que, impossibilitados de continuar os estudos superiores, e desprezando a indústria mecânica ou outra qualquer, tornar-se-iam inúteis e até perigosos" (Borges, 1856, p. 28). Essa posição era bastante recorrente nos discursos de autoridades e intelectuais brasileiros e, como corrobora Jean-Claude Caron,

do Antigo Regime ao fim do século 19, inúmeros são os publicistas ou os políticos a exprimir seu receio de ver as classes populares terem acesso ao ensino secundário e reivindicarem uma posição social não correspondente às suas competências nem aos seus 'interesses': o que Richelieu e Colbert, mas também Voltaire e Rousseau, afirmam antes da Revolução (muita instrução nas classes populares ameaça os equilíbrios social e econômico da sociedade), outros (Balzac, Stendhal, Reybaud) o reafirmam no século 19 , temendo as consequências sociais - às claras, a insurreição ou a revolução - de um excesso de letrados condenados à inatividade. (Caron, 1996, p. 152)

Portanto, a defesa da criação de estabelecimento público de ensino secundário com internato, ou a criação deste nos liceus já existentes, muito recorrente nos relatórios de presidentes ou autoridades da instrução das províncias do Pará, Maranhão, Piauí, Ceará, Rio Grande do Norte, Bahia, Paraíba, Alagoas e Sergipe, principalmente nas décadas de 1850 a 1870, deve ser entendida como uma estratégia para atender, principalmente, aos anseios pelo ensino secundário das elites das províncias. Não se pode olvidar que eram esses segmentos que podiam arcar com os custos do internato que correspondiam principalmente ao pagamento da mensalidade ou pensão, preparação do enxoval e pagamento da jóia para uso dos utensílios do estabelecimento: cama, colchões, colcha, travesseiros, lavatório, material da sala de banho, bacias, copos, talheres. Também eram pagos em separado os serviços de lavagem e gomagem de roupas, os gastos com médico e botica, as atividades complementares de ensino - belas-artes ou artes de recreio -, e, em alguns estabelecimentos, as férias passadas no estabelecimento. Assim, o internato público não se confundia com internato gratuito. O termo público significava que seria criado e mantido pelo governo provincial, que para isso deveria cobrar pensões dos alunos que fizessem uso de serviços específicos do internato. 
$\mathrm{Na}$ argumentação das autoridades provinciais a adoção do internato possibilitaria que jovens de regiões interioranas pudessem cursar o ensino secundário nos liceus das capitais, como defendia, em 1860, Herculano Ferreira Penna, presidente da Província da Bahia, em sua manifestação à Assembleia Legislativa: "o Liceu deve ser convertido em um internato [...] para que o benefício que este estabelecimento presta às famílias da capital chegue também as que moram fora dela" (Penna, 1860, p. 52). Igualmente seria a solução para evitar que os moços recorressem a outra província em busca de instrução, na opinião do presidente da Província do Piauí:

Todos os moços que se destinam a formaturas de medicina e direito aprendem em colégios na Bahia e no Maranhão ou em Pernambuco todos os seus preparatórios, e isso porque não há na província um internato no qual possam os pais de família confiar seus filhos. Se assim é, e se gastamos tanto dinheiro com o Liceu sem resultados maiores, não se perderia nada em organizar um internato à custa da província, que oferecesse a todos os pais de família as seguranças indispensáveis para educação de seus filhos. (Moacy, 1939, p. 257)

A defesa do internato nos estabelecimentos de ensino secundário provincial se repete em outros relatórios de presidentes de províncias. Em 1854 o conselheiro Sebastião do Rego Barros, presidente da Província do Pará, defendia a reorganização do "Liceu Paraense em um colégio, onde ensinando-se as atuais matérias e outras que lhe faltam, se admitisse o internato" (Barros, 1854, p. 12). Na Província do Maranhão, o presidente Francisco Xavier Paes Barreto relatava que o Liceu Maranhense, situado no pavimento térreo do Convento do Carmo, na capital da província, apresentava pouca utilidade por causa do pequeno número de alunos matriculados, ressaltando que essa situação poderia ser diferente se o Liceu fosse "convertido em um internato, à semelhança ao Pedro II" (Barreto, 1858). Em 1870, a lei n. 920, de 21 de junho de 1870, autorizou o presidente da Província do Maranhão a reformar o regulamento da instrução e a converter o liceu em internato (Maya, 1871, p. 8). Entretanto, no ano de 1871, o presidente Gomes de Castro comunicou à Assembleia Legislativa Provincial que não tinha dado efetividade à criação do internato no Liceu Maranhense, justificando que tal medida importaria em avultada despesa para os cofres da província e também porque o modelo já não vinha demonstrando progressos em outras províncias onde fora tentado e mesmo por desacreditar no princípio do internato como modelo ideal para educar (Castro, 1871, p. 17).

Na Província de Pernambuco, em 1855, o presidente conselheiro dr. José Bento da Cunha e Figueiredo expunha à Assembleia Legislativa Provincial a necessidade de instalação, apesar das avultadas despesas, de um internato no liceu público. Para isso também comunicava ao poder legislativo que, na falta de um edifício com dependências adequadas, havia determinado a elaboração de uma planta para o internato (Figueiredo, 1855, p. 13).

As iniciativas de adoção do internato em estabelecimentos públicos de ensino secundário, em geral, eram idealizadas conservando a gratuidade do ensino, mas exigindo o pagamento da pensão referente a alojamento e às refeições. Assim, uma forma utilizada para a criação do internato foi a implantação deste por contrato entre o governo e a iniciativa particular. Neste caso, cabia ao governo subvencionar o ensino - 
material escolar, professores públicos, prédio - e ao empresário o fornecimento de pensão e demais necessidade de um internato, pelas quais deveria ser remunerado pelas pensões pagas pelos alunos pensionistas e meio-pensionistas. Esta modalidade foi tentada, entre outras, na província de Sergipe, com a criação de dois internatos nas cidades de Laranjeiras e Estância, localizadas no interior da província (Barbosa, 1855). Como dizia o dr. Guilherme Pereira Rebello, inspetor geral da Instrução da Província de Sergipe, tais internatos não passavam de estabelecimentos particulares que recebiam da Província a subvenção a título de socorro (Rebello, 1861). Também foi idealizado na Província de Pernambuco um internato com essas características: "Um estabelecimento da ordem do internato serão suficientemente compensadas não só pela pensão, que devem pagar os alunos internos e externos, como pela grande utilidade que ele há de prestar à província" (Figueiredo, 1855). Nesse mesmo sentido pronunciava-se, em 1851, o presidente da Província do Piauí, afirmando que

a criação de um internato no qual funcionassem as aulas do liceu me parece a medida única na atualidade, capaz de derramar na província a instrução secundária. Estou convencido que a despesa não seria aumentada, porque se devia exigir dos pais de família uma módica pensão pelo alimento e vestuário de seus filhos, e também quanto bastasse para indenizar a província das despesas com eles, e com o acréscimo de ordenado de um diretor que residisse no internato. A não ser isso, conviria que estimulasse por qualquer forma uma empresa particular, conquanto me persuado de que isso seria baldado. (Moacy, 1939, p. 255)

\section{Internatos provinciais: a experiência sergipana}

Em Sergipe, desde o ano de 1845, era defendida a ideia de reunirem-se as aulas secundárias em um estabelecimento na capital da província, onde os professores comparecessem diariamente para ministrar suas lições e os moços pudessem concorrer a ele sem a necessidade de buscarem fora da província essa instrução. No ano de 1847 a ideia foi posta em prática pelo presidente da Província, o cônego José Francisco Menezes Sobral, com a fundação do Liceu de São Cristóvão. O Liceu, que sempre funcionou sem internato, iniciou suas atividades no ano de 1848 com a reunião de cinco cadeiras. Eram ministradas disciplinas requeridas nos exames preparatórios dos cursos superiores do Império: Latim, Francês, Inglês, Geografia e História, Geometria, Filosofia e Retórica.

Entretanto, desde a fundação do Liceu de São Cristóvão, os relatórios da Congregação do estabelecimento apresentavam números (Barbosa, 1854) indicadores de uma baixa frequência e pouco aproveitamento ou adiantamento dos alunos. Como fatores do fracasso (Rebello, 1861) do Liceu eram apontadas as condições da própria localização da instituição na cidade de São Cristóvão, capital da Província, mas que, na época, não vinha apresentando desenvolvimento econômico. E, mesmo sendo a sede do governo provincial, tinha dificuldades de instalações e de comunicação com as principais cidades da província. Igualmente, doenças (Andrade, 1851) que acometiam a população concorriam para o estado de abandono em que se achava o Liceu. Somava-se a essas razões o fato de que as elites residentes, principalmente nas cidades de Estância e Laranjeiras, principais centros econômicos da província, continuavam com o costume de 
enviar seus filhos para os colégios-internatos fora da província, visto que os exames realizados no Liceu de São Cristóvão não eram reconhecidos para o ingresso nas Faculdades do Império.

A relação entre custos elevados e baixa frequência e aproveitamento dos alunos do Liceu motivaram o debate, nos primeiros anos da década de 1850, a respeito da continuidade do estabelecimento. Nesses debates o internato era apresentado como medida a ser adotada para o sucesso de um estabelecimento de ensino secundário na Província. Além do liceu, para o presidente da Província, Inácio Joaquim Barbosa, as aulas avulsas, em geral, pouca utilidade prestavam, porque lutavam com o embargo ou falta de internato (Barbosa, 1854).

Contudo, havia quem defendesse, antes de extinguir o Liceu ou transferi-lo para outra cidade da Província, a continuação do estabelecimento em São Cristóvão com a criação de um internato que pudesse atrair alunos de outros pontos da Província, movimentando as matrículas e frequência do estabelecimento. Entretanto, como na visão dos governos provinciais a criação de um internato público acarretaria consideráveis despesas e dificuldades no seu funcionamento, avaliou-se mais prudente adiá-la para época em que as rendas da Província estivessem em melhor situação (Silva, 1853). Quanto à ideia de transferir o Liceu para a cidade de Estância ou Laranjeiras julgava-se que a medida não resolveria o problema, pois essas cidades, mesmo sendo as mais populosas da província, sozinhas não teriam condições de oferecer um número de matrículas que justificasse a transferência.

Igualmente as dificuldades de comunicação da época, e de uma população predominantemente rural, a criação de um estabelecimento de ensino secundário com internato continuou sendo apresentada como medida acertada a fim de atrair jovens de outros pontos da Província (Barbosa, 1854). Não obstante, em 1855, esse mesmo presidente da Província argumentava que a criação de um internato público não seria posta em prática, pois a experiência do internato em outras províncias já havia demonstrado que somente em estabelecimentos particulares podia produzir benefícios correspondentes às despesas que o modelo acarretava, e porque "o interesse, que tem o empresário de acreditar o estabelecimento para aumentar os seus lucros, desafia melhor a fiscalização e zelo de sua parte" (Barbosa, 1855).

Assim, visto que o internato público não teria condições de prosperar, deveria o governo estimular e subvencionar a criação de internatos particulares para o oferecimento do ensino secundário. Adotando essa ideia, em 1855, o presidente Inácio Joaquim Barbosa determinou a contratação de dois colégios particulares, um em Estância e outro em Laranjeiras, para que neles fossem reunidas cadeiras do ensino secundário público e o funcionamento de internatos.

No ano da escolha das cidades de Estância e Laranjeiras para a instalação dos internatos, a capital da Província, por ato do mesmo presidente Inácio Joaquim Barbosa, já havia sido transferida para Aracaju. Entretanto, avaliou-se que a nova capital não apresentava condições necessárias - prédios, população, salubridade - para receber estabelecimentos de ensino secundário como os que foram criados em Estância e Laranjeiras. 
Os colégios-internatos de Estância e Laranjeiras, de acordo com a organização proposta no seu regulamento (Regulamento, 1854) e no contrato entre o governo provincial e os respectivos empresários, estavam subordinados à Inspetoria Geral das Aulas e tinha uma natureza jurídica híbrida (Barbosa, 1855), ou seja, um externato público e gratuito sem distinção de disciplinas e um internato particular. Ao diretor ou empresário do colégio, pessoa de reconhecida probidade e conhecimentos literários, cabia manter o internato e semi-internato com o recebimento de pensões e meias pensões, oferecer disciplinas complementares como dança e música, pagas pelos interessados; manter a ordem e disciplina, zelando pelo bom funcionamento do estabelecimento; fiscalizar os professores, presidir os exames anuais e de tudo dando contas ao inspetor geral de ensino (Regulamento, 1854).

Ao governo provincial cabia o pagamento da remuneração dos professores e o custeio de aluguel de casas e materiais didáticos para o funcionamento dos estabelecimentos. Esses colégios eram estabelecimentos subvencionados pelo governo, funcionando em casas alugadas, com cômodos arranjados para receber alunos internos. O presidente da Província, Inácio Joaquim Barbosa, justificava a subvenção do governo aos colégios como uma medida capaz de incentivar os empresários a investir em um empreendimento que demandava razoáveis investimentos, mas sem muitas garantias de sucesso. Segundo o presidente Inácio Barbosa,

um internato particular, que possa inspirar confiança ao público pelo seu bom regime, e hábeis mestres, acarreta fortes despesas, e à essas não quererá sem duvida sujeitar-se um empresário na eventualidade de poder ou não atrair ao seu Colégio os alunos, que hoje vão buscar instrução fora da Província, visto, o hábito, e a preocupação, que naturalmente d'ele deriva, de que só fora da Província se aprende. E o fato ai está, porque até hoje não se tem estabelecido na Província um único colégio regular. (Barbosa, 1855, p. 11)

Com a criação dos internatos nas cidades de Estância e Laranjeiras o presidente Inácio Barbosa esperava que os estabelecimentos funcionassem como polos de atração de alunos oriundos, respectivamente, do Sul e do Norte da província. A medida procurava responder, também, aos anseios pelo ensino secundário das elites e até de estratos médios da população da província sergipana, que eram os segmentos que podiam arcar com os custos do internato. A escolha da cidade de Estância para sediar um dos internatos deveu-se a sua situação geográfica, que, na época, Ihe garantia a prosperidade econômica pela atividade comercial (Nunes, 2006).

O internato do Colégio Público de Estância, sob a direção do dr. Antonio Ribeiro, começou a funcionar em 1855 com uma matrícula de 48 alunos (Barbosa, 1855). A pequena matrícula inaugural foi motivada, provavelmente, pela epidemia de cóleramorbus que assolou Sergipe em 1855. No ano de 1858 o citado diretor informava ao inspetor geral das Aulas, dr. Pedro Autran da Matta Albuquerque Junior, o bom rendimento dos alunos do internato (Albuquerque, 1859). Mas, a despeito dos resultados positivos e de estar em melhores condições do que o Colégio de Laranjeiras, de forma geral o internato de Estância não apresentava um aspecto muito lisonjeiro. Assim, no ano 
de 1959, o diretor Antonio Ribeiro Lima relatava ao dr. Autran, inspetor geral das aulas, problemas que ele vinha enfrentando com a falta de assiduidade dos alunos ao estabelecimento:

\begin{abstract}
Sinto profundamente não poder deixar de censurar o procedimento repreensível de muitos alunos a respeito de sua assiduidade; é raro, e pode se dizer que nunca ter o professor a satisfação de encontrar na aula todos os matriculados; muitos vêm no meio dos exercícios d'aula, e quase no fim, e o que é mais escandaloso; alguns tendo estado nas proximidades do internato antes da hora de aulas à espera delas se retiram apenas avistam o professor ou se deixam ficar a conversar por aí sem entrar para aula, e não me resta, e nem aos professores outros recursos, senão aconselhar, repreender e avisar a seus pais como muitas vezes temos feito, sem que se tenha diminuído o desgosto que nos causa tal procedimento. (Albuquerque, 1859, p. 11)
\end{abstract}

As dificuldades do Colégio de Estância continuaram no decorrer dos anos. Nesse sentido foi a impressão do imperador D. Pedro II quando esteve, no ano de 1860, na Província de Sergipe. Visitando a cidade de Estância o imperador esteve no colégiointernato subvencionado pelo governo provincial, tendo deixado os seguintes registros no seu diário sobre o estabelecimento:

Há um colégio particular na Estância com professores e casa pagos pela província, espécie de empreitada. [...] Internato - só tem 6 internos, os mais externos, casa mesquinha 58 estudantes - estudantes de geometria 2 fracos, 2 de latim sofríveis, 2 de francês bons, parecendo-me bom o professor - 1 de geografia pouco adiantado, o professor não é bom. (Revista, 1965, p. 68)

A cidade de Laranjeiras, localizada no Norte da província, à margem esquerda do rio Cotinguiba, região produtora de cana-de-açúcar, foi a escolhida pelo presidente Inácio Joaquim Barbosa para a instalação do outro colégio público com internato. Desde o início do século 19 a cidade de Laranjeiras se destacava como centro principal do comércio importador e exportador da província e mantinha comunicação direta com a Europa, Bahia, Pernambuco e Rio de Janeiro pela navegação marítima (Nunes, 2006). Acreditavase que este fator podia facilitar a atração de jovens à cidade em busca do ensino secundário.

A direção do Colégio Público de Laranjeiras, subvencionado pelo governo provincial, coube ao professor de Geometria e Francês Manuel Odorico Mendes de Amorim. As aulas ministradas eram de Latim, Francês, Geometria, Filosofia, Geografia e História. Desde sua fundação o colégio de Laranjeiras apresentava um número pequeno de matrículas e, sobretudo, uma insignificante procura pelo internato. Parecem não ter surtido os efeitos esperados os anúncios que o diretor fez publicar nos jornais no ano de 1856, tentando persuadir os pais de famílias a matricularem seus filhos no estabelecimento (Anúncio, 1856), pois, nesse ano, o estabelecimento recebeu apenas dois internos dos 32 alunos matriculados. À falta de alunos internos juntava-se a falta de materiais escolares, como globo terrestre, planetário, mapas geográficos e cadeiras escolares (Albuquerque, 1859). 
O diretor Manuel Odorico Mendes de Amorim defendia que as razões para o infortúnio do estabelecimento eram as mesmas que estavam determinando o fracasso de instituições dedicadas ao ensino secundário em outras províncias, ou seja, faltava uma regulamentação homogênea e uniforme da instrução secundária no país e, principalmente, que fossem reconhecidos os certificados e diplomas dos estabelecimentos provinciais para o ingresso nas faculdades do Império. Segundo o diretor, mantido o monopólio dos exames preparatórios pelas faculdades, o internato de Laranjeiras estava fadado ao insucesso. Ele dizia: "Não espero obter pensionário e nem também nos anos anteriores os tenho obtido, tendo seis apenas frequentando este ano as aulas do estabelecimento" (Albuquerque, 1859, p. 14). Ainda segundo o mencionado diretor, a mesma sorte acompanhava os colégios particulares da cidade, pois os pais preferiam gastar com as pensões dos estabelecimentos de Salvador ou de outras províncias onde estavam sediadas as faculdades e seus filhos podiam ter mais sucesso nos exames preparatórios.

Diante da insignificante procura o Colégio de Laranjeiras foi extinto (Sergipe, 1859; Galvão, 1860) em 2 de novembro de 1859. inspetor Guilherme Pereira Rabello justificava a dissolução do internato de Laranjeiras como

a justa satisfação ao reclamo público contra a existência de um estabelecimento, que não passava de uma sinecura, que era mesmo a mais flagrante ironia de um estabelecimento literário. A exceção das aulas de latim e francês, que eram freqüentadas a primeira por 35 alunos e a segunda por 13 , todas as demais aulas não contavam mais de 4 alunos, alguns dos quais se não haviam inscrito na matrícula, senão com um meio cômodo de serem dispensados do serviço da Guarda Nacional. Ora não é justo que a Província tire tão pouco proveito de seus sacrifícios, não é justo que quando Ela se esforça por derramar sobre seus filhos a instrução superior, receba na face uma gargalhada de zombaria e de escárnio em paga de sua generosa solicitude. (Galvão, 1860, p.11)

De semelhante forma, em 1860, o governo provincial, objetivando diminuir as despesas da Província (Galvão, 1860), extinguiu diversas cadeiras do ensino primário e secundário, e, igualmente, o internato de Estância foi extinto (Rebello, 1861). Para o inspetor Guilherme Pereira Rabelo era necessário identificar as causas do insucesso dos mencionados internatos, que haviam sido criados para estimular as matrículas no ensino secundário da Província:

Cumpre porém investigar as causas da pouca fortuna destes internatos. A Província regurgita de moços hábeis e talentosos; e com quanto as letras não tenham sido elevadas àquele grau de consideração, que devem merecer em qualquer País, que aspira aos foros de civilizado, com tudo não são tidas em desprezo por aqueles que podem dar a seus filhos uma educação literária superior. As nossas academias contam muitas dezenas de filhos da Província, os quais vão adquirir fora d'ela os conhecimentos humanitários necessários, como preparação para os estudos acadêmicos; entretanto o Liceu de São Cristovão e os internatos de Estância e Laranjeiras; tiveram a fortuna de contarem sempre professores hábeis e zelosos no cumprimento de seus deveres (Rebello, 1861, p. 135) 
Mesmo tendo sido abertos estabelecimentos nas principais cidades da Província, com população e fortuna capazes de demandar estudantes para os internatos, o problema da insuficiência de matrículas nos estabelecimentos de ensino secundário continuou. As famílias preferiram continuar enviando seus filhos para os colégiosinternatos sediados nas capitais sedes das faculdades. Assim, o não reconhecimento dos estudos e exames realizados nos estabelecimentos provinciais de ensino secundário era apresentado como principal fator do fracasso desse ramo de ensino em Sergipe e em outras províncias (Rebello, 1861). Conforme o pensamento das autoridades da instrução das províncias, sob essas condições nem mesmo a criação de internatos pelo governo provincial teria condições de prosperar.

\section{Razões para o insucesso dos internatos provinciais}

$\mathrm{Na}$ maior parte dos casos a criação do internato nos estabelecimentos públicos provinciais ficou no campo das ideias ou na aprovação de leis que não chegaram a ser executadas. Na Província da Paraíba, em 1856, chegou a ser sancionada uma lei autorizando o governo provincial a converter o Liceu Provincial em um internato, mas logo no ano seguinte não havia sido executada por falta de um edifício que oferecesse acomodações adequadas. Todavia, o diretor da Instrução Pública da Paraíba, Henrique Victor Lima, defendia que a criação do internato no Liceu não deveria ser abandonada, pois o internato garantiria "comodidades aos pais do interior da província, que, para promoverem a instrução de seus filhos, são forçados atualmente, ou a confiá-los à direção de colégios particulares" (Lima, 1857, p. 5).

As razões, recorrentemente apresentadas pelos presidentes das províncias nas décadas de 1850 a 1870, para a não conversão dos liceus provinciais em internato, como estava previsto em leis ou em autorizações legislativas provinciais, a exemplo das províncias da Sergipe, Pernambuco, Paraíba, Alagoas, Pará, Maranhão, foram, entre outras, os valores elevados requeridos pelo empreendimento, falta de um diretor habilitado, inexistência de um edifício adequado e o insucesso que o modelo já havia apresentado em outras províncias em que fora tentado. Algumas dessas razões são encontradas, em 1856, no discurso de Antonio Coelho de Sá e Albuquerque, presidente da Província de Alagoas, justificando-se perante a Assembleia Provincial a não substituição do Liceu por um internato como fora autorizado por lei aprovada em 1854 pela Assembleia Provincial (Albuquerque, 1856, p. 30).

A descrença no valor pedagógico do internato também foi outra justificativa apresentada por presidentes de províncias para a não efetividade do modelo na instrução pública. Esta razão aparece no discurso de Gomes Castro, presidente da Província do Maranhão. Argumentando sobre distinções entre instrução e educação, ele desacreditava na capacidade do internato para educar e formar cidadãos ativos:

Confunde-se em tais estabelecimentos a educação e a instrução, sendo aquela confiada a uma autoridade estranha à família, que o amor não esclareceu nem mitiga, o que não pode deixar de exercer funesta influência no espírito e caráter dos mancebos que lhes são subordinados. A educação incumbe à família; o poder público, por mais solícito que seja, não pode substituí-la convenientemente em tão árdua e importante missão. Limite-se pois a ministrar à mocidade mestres moralizados e hábeis, e deixe aos pais a responsabilidade e a glória de educar seus filhos. Não 
satisfazem, diz um notável escritor, nem ao espírito, nem ao corpo, os nossos liceus de internatos, meio seminários meio quartéis. Falece-lhes ar e espaço e ainda mais aquela liberdade que, desde a infância, ensina o indivíduo a dirigir-se e a respeitar-se. A obediência passiva, aliás necessária onde há aglomeração de homens, é péssima educação da vontade; faz soldados e padres, mas nunca cidadãos (Castro, 1871, p. 17)

De fato, mostrou-se comum nos discursos de alguns presidentes ou autoridades da instrução pública de províncias utilizarem como justificativa para o não estabelecimento de internatos a reprovação do modelo pela sua incapacidade para educar corretamente. São elucidativos os argumentos apresentados pelo dr. Guilherme Pereira Rebello, inspetor geral da instrução da Província de Sergipe que, também ao mostrar as diferenças entre educação e instrução, opinava pela impossibilidade da primeira ser bem desenvolvida nos internatos. Segundo o referido inspetor a educação e a instrução tinham por fim o aperfeiçoamento moral, mas não deviam ser confundidas. Enquanto a instrução - educação teórica - tinha como objetivo principal o desenvolvimento e ilustração do intelecto, a educação - educação prática -, ao contrário, tinha como fim a direção das inclinações, da vontade, das paixões, a fim de que o indivíduo concorresse para o desenvolvimento da sociedade como um elemento de "moralidade, de respeito e obediência às leis, e aos direitos de seus concidadãos, de subserviência aos deveres proscritos pela Religião, de amor ao trabalho, e finalmente como um elemento de grandeza e felicidade da nação" (Rebello, 1861, p.25).

Para o dr. Guilherme Pereira Rebello somente na família a "educação prática" podia ser incutida, pois era sob os cuidados afetuosos da mãe "que a tenra infância e a juventude aprendem a identificarem-se com estes bons hábitos, com estes costumes puros, com estas maneiras delicadas, que distinguem a primeira vista o homem bem educado" (Rebello, 1861, p.25). Disso decorria a impossibilidade dos internatos, mesmo os subvencionados pelo Estado, de educarem ou transmitirem valores aos indivíduos. $\mathrm{E}$, mesmo considerando a importância dos internatos particulares para a instrução da juventude, afirmava que não omitiria, no interesse da moralização do povo, que a "educação prática" não podia ser transmitida por eles, mas "sim no aconchego do lar doméstico; porque o reitor de um internato por mais solicito e paternal que seja, por mais virtuoso e sábio, jamais pode substituir a mãe de família" (Rebello, 1861, p.27).

$\mathrm{O}$ inspetor dr. Guilherme Pereira Rebello exemplificava o seu pensamento sobre os internatos citando o Ginásio Baiano, dirigido pelo dr. Abílio Cesar Borges. Segundo ele, esse renomado estabelecimento de ensino podia ser citado como um internato em que existiam zelo, dedicação, pontualidade, ordem, aplicação, bons mestres e asseio. Ainda conforme o doutor Guilherme, os alunos do Ginásio Baiano apresentavam notáveis progressos nas letras, moralidade, bons costumes, maneiras delicadas e polidas. Mesmo assim, ousava dizer que a "educação prática" era aprendida de forma mecânica, "como se aprende uma tática, uma manobra, do que identificada com o coração, e nascida do que há n'alma de mais sentimental e afetuoso" (Rebello, 1861, p.25).

O dr. João da Matta Machado, em sua tese de doutoramento pela Faculdade de Medicina do Rio de Janeiro (1875), igualmente compartilhava da ideia que a educação era impossível de ser realizada nos internatos. Para ele, a "educação do coração" somente podia ser ministrada na família, era impossível realizá-la nos internatos leigos ou religiosos por mais bem dirigidos que fossem. Segundo o citado facultativo, o regime 
cenobítico $^{1}$ dos internatos era capaz de destruir todos os ensinamentos recebidos "durante os primeiros anos da vida, no interior da família mais virtuosa; a falta de uma terna mãe durante os longos anos de estudos clássicos deixa traços indeléveis nos corações mais bem formados" (Machado, 1875, p. 62). Argumentava, ainda, que o internato não preparava os jovens para viver em sociedade, pois quando estes deixavam o colégio mostravam-se inexperientes para enfrentar as dificuldades ou resistir aos vícios. No cotidiano do internato aprendiam a obedecer com servilismo e hipocrisia. E, mais, a falta de convivência com o sexo oposto acarretava como inconveniente não poderem ter critério necessário para escolher uma mulher para esposa e não poderem desfrutar da salutar influência que exerciam as mulheres sobre os costumes.

Todavia, arrazoava o dr. João da Matta Machado, em certas circunstâncias, os pais eram obrigados a enviar seus filhos aos internatos. Neste caso, era aconselhável que o diretor do estabelecimento escolhido fosse casado e portador de algumas qualidades para minimizar os perigos do internato. $O$ diretor ou professor de um internato deveria exercer o magistério como sacerdócio, ter uma instrução sólida, firmeza de caráter, retidão de consciência, abnegação completa, paciência inquebrantável e amar os meninos que lhe fossem confiados. Mas segundo o dr. Machado o que se via nos colégios mais bem dirigidos, nas casas de educação mais afamadas da Corte Imperial era o "diretor, seco, áspero e egoísta, armado constantemente de nojenta férula, odeia profundamente seus alunos, e é ainda mais odiado por eles!" (Machado, 1875, p.63).

Contudo, a descrença na capacidade educativa do internato não era uma ideia absoluta. Quanto a isso são elucidativas as palavras do presidente da Província do Piauí: "Continuo a pensar que o Liceu nenhuma utilidade prestará à província enquanto não for nele instalado o internato [...]. Tais estabelecimentos são úteis porque reúnem a dupla vantagem da instrução e da educação" (Moacy, 1939, p. 258). A mesma confiança na capacidade pedagógica do internato é expressa nas palavras de José Antonio Saraiva, presidente da Província de Alagoas: "um Internato serve melhor à educação e à instrução, e estabelece sobre os professores e sobre os discípulos uma inspeção ativa e permanente, que é apreciada, censurada, julgada por todos os pais de família com muito vigor" (Saraiva, 1854, p. 13). E, na Província do Ceará, o presidente concluía que a baixa frequência no liceu público decorria, dentre outros fatores, da concorrência que lhe fazia um colégio particular com internato instalado na capital da Província, pois esse colégiointernato garantia maior direcionamento na instrução dos educandos e, portanto, era mais acreditado pelas famílias residentes no interior da província (Pereira, 1864, p. 27).

\section{Considerações finais}

Os discursos ou medidas tomadas por autoridades provinciais mostram que durante o século 19 o internato, amplamente utilizado nos colégios particulares, também foi pensado e utilizado na instrução pública, principalmente com o intuito de desenvolver os estabelecimentos provinciais de ensino secundário que se ressentiam com a falta de alunos. Segundo as autoridades provinciais o internato estimularia os liceus provinciais,

\footnotetext{
${ }^{1}$ Cenobítico: "indivíduo que leva vida, retirada mas em comum com outros que têm seus mesmos interesses, princípios ou prerrogativas”. In: FERREIRA, Aurélio Buarque de Holanda. Novo dicionário da língua portuguesa. Rio de Janeiro: Nova Fronteira, 1975, p. 305. 
aumentando a demanda, e possibilitaria que jovens de regiões interioranas pudessem cursar o ensino secundário nos liceus das capitais ou evitaria a saída deles para outras províncias em busca de instrução.

A defesa do internato deve ser entendida como uma estratégia para atender, principalmente, aos anseios pelo ensino secundário das elites das províncias, pois podiam arcar com os custos do internato. Desta forma, as iniciativas de adoção do internato em estabelecimentos públicos de ensino secundário eram propostas com a conservação da gratuidade do ensino, mas exigindo o pagamento da pensão referente à cama e comida: pensionato. Uma proposta de criação de internatos na instrução pública ocorreu pelo contrato entre o governo e um particular. O governo subvencionava o ensino - material escolar, professores públicos, prédio -, e ao empresário cabia o fornecimento de pensão e demais necessidades de um internato pelas quais deveria ser remunerado pelas pensões pagas pelos alunos pensionistas e meio-pensionistas. Todavia, na maior parte dos casos, a criação do internato nos estabelecimentos públicos de ensino secundário das províncias ficou no campo das ideias ou na aprovação de leis que não chegaram a ser executadas.

A criação de internato não resolveu o problema da insuficiência de matrículas nos estabelecimentos de ensino secundário provinciais onde fora tentado. $O$ não reconhecimento dos estudos e exames realizados nos estabelecimentos de ensino secundário provinciais foi o principal fator do fracasso desses estabelecimentos. Conforme o pensamento de autoridades provinciais da instrução, sob essas condições, nem mesmo a criação de internatos em colégios subvencionados pelo governo provincial teria condições de progredir. As famílias preferiram continuar enviando seus filhos para os colégios-internatos sediados nas províncias sedes das faculdades.

\section{Referências}

ANÚNCIO. Correio Sergipense. Aracaju, p. 4, 27 fev. 1856.

ANDRADE, Amancio João Pereira de. Fala do presidente da Província de Sergipe à Assembléia Provincial, em 11 de janeiro de 1851. [São Christovão: Typographia Provincial de Sergipe, 1851.

ALBUQUERQUE, Antonio Coêlho de Sá e. Fala do presidente da Província de Alagoas no ano de 1856. Recife: Typ. de Santos \& Companhia, 1856.

ALBUQUERQUE JUNIOR, Pedro Autran da Matta. Relatório do Inspetor Geral das Aulas, 1859. (Anexo). In: BROTERO, João Dabney D'Avellar. Relatório do presidente da Província de Sergipe em 7 de março de 1859. Aracaju: Typographia Provincial de Sergipe, 1859, p. 1-16.

AZEVEDO, Manuel Antônio Duarte Moreira de. O regime de Internato nos estabelecimentos de instrução secundária e nas escolas normais. In: CONGRESSO DA INSTRUÇÃO. 1884. Rio de Janeiro. Atas e pareceres... Rio de Janeiro: Typographia Nacional, 1884.

BARBOSA, Inácio Joaquim. Relatório do presidente da Província de Sergipe em $1^{\circ}$ de março de 1855. Typographia Provincial de Sergipe, 1855.

BARBOSA, Inácio Joaquim. Relatório do presidente da Província de Sergipe em $1^{\circ}$ de março de 1855. Typographia Provincial de Sergipe, 1855.

BARRETO, Francisco Xavier Paes. Relatório do presidente da Província do Maranhão em 13 de abril de 1858. São Luiz do Maranhão: Typ. da Temperança, 1858. 
BARROS, Sebastião do Rego. Fala do presidente da Província do Pará à Assembléia Legislativa Provincial no dia 15 de agosto de 1854. Pará: Typ. da Aurora Paraense, 1854.

BORGES, Abílio Cesar. Relatório sobre a Instrução Pública da Província da Bahia. Bahia: Typographia de Antonio Olavo da França Guerra e Comp., 1856.

BRASIL. Decreto de 2 de dezembro de 1837. Converte o Seminário de S. Joaquim em colégio de Instrução Secundária, com a denominação de Colégio de Pedro II, e outras disposições. Rio de Janeiro, 1837.

BRASIL. Decreto n. 2006 de 24 de outubro de 1857. Aprova o Regulamento para os colégios públicos de Instrução Secundária do Município da Corte. Rio de Janeiro, 1857.

BRASIL. Regulamento n. 8, de 31 de janeiro de 1838. Contém os estatutos para o Colégio de Pedro II. Rio de Janeiro, 1838.

CÂMARA, Euzébio de Queiroz Mattoso Coutinho. Relatório do estado da Instrução Primária e Secundária do Município da Corte apresentado em 15 de fevereiro de 1856. (Anexo). In: FERRAZ, Luiz Pedreira de Couto. Relatório apresentado à Assembléia Geral Legislativa pelo Ministro e Secretário de Estado dos Negócios. Rio de Janeiro: Typographia Nacional, 1856.

CÂMARA, Euzébio de Queiroz Mattoso Coutinho. Relatório da Inspetoria Geral da Instrução Primaria e Secundária do Município da Corte apresentado em 25 de abril de 1858. (Anexo K). In: FERRAZ, Luiz Pedreira do Coutto. Relatório apresentado à Assembléia Geral Legislativa pelo Ministro e Secretário de Estado dos Negócios do Império. Rio de Janeiro: Typographia Universal de Laemmert, 1857, p. 1-24.

CARON, Jean-Claude. Os jovens na escola: alunos de colégios e liceus na França e na Europa (fim do séc. XVIII - fim do séc. XIX). In: LEVI, Giovanni; SCHMITT, Jean-Claude. História dos jovens: a época contemporânea. São Paulo: Companhia das Letras, 1996, p. 137-194.

CASTRO, Gomes de. Relatório do presidente da Província do Maranhão à Assembléia Legislativa Provincial em 3 de maio de 1871. São Luiz do Maranhão: Typ. B. de Mattos, 1871.

CHWARCZ, Lilia Moritz. As barbas do imperador: D. Pedro II, um monarca nos trópicos. São Paulo: Companhia das Letras, 2010.

CONCEIÇÃO, Joaquim Tavares. Internar para educar: colégios-internatos no Brasil (1840-1950). Salvador: UFBA, 2012. 322f. Tese (doutorado em História). Faculdade de Filosofia e Ciências Humanas, Universidade Federal da Bahia.

CONGRESSO DA INSTRUÇÃO. 1884. Rio de Janeiro. Atas e pareceres... Rio de Janeiro: Typographia Nacional, 1884.

CUNHA, Balbino Candido da. Esboço de uma Higiene de colégios, aplicável aos nossos; regras principais tendentes á conservação da saude, e ao desenvolvimento das forças físicas e intelectuais, segundo as quais se devem reger os nossos colégios. Rio de Janeiro: Typographia Universal de Laemmert, 1854.

DORIA, Escragnolle. Memória histórica do Colégio de Pedro Segundo. 1837-1937. Brasília: Inep, 1997.

FERREIRA, Aurélio Buarque de Holanda. Novo dicionário da Língua Portuguesa. Rio de Janeiro: Nova Fronteira, 1975. 
FIGUEIREDO, José Bento da Cunha e. Relatório do presidente da Província de Pernambuco à Assembléia Legislativa Provincial no ano 1855. Recife: Typ. de M. F. de Faria, 1855.

FRIAS, David Correia Sanches de. A mulher, sua infância, educação e influência na sociedade. Artigos publicados em outubro de 1879 no jornal A Província do Pará. Pará: Tavares Cardoso \& C. Livraria Universal, 1880, p. 54.

GALVÃO, Manoel da Cunha. Relatório do presidente da Província de Sergipe em 13 de agosto de 1860. [Aracaju]: Typographia Provincial de Sergipe, 1860.

HAIDAR, Maria de Lourdes Mariotto. O ensino secundário no Brasil Império. São Paulo: USP, 2008.

INTERNATO do Imperial Collegio de Pedro II. Rio de Janeiro: Imprensa Nacional, 1885.

LIMA, Henrique Victor. Relatório do Director da Instrução Pública. (Anexo) In: CUNHA, Manoel Clementino Carneiro da. Relatório do presidente da Província da Paraíba do Norte à Assembléia em 1 de agosto de 1857. Paraíba: Typ. de José Rodrigues da Costa, 1857.

MACHADO, João da Matta. Da educação física, intelectual e moral da mocidade no Rio de Janeiro da sua influência sobre a saúde. Typographia de G. Leuzinger \& Filhos, 1875.

MAIA, João Carlos de Oliva. O regime de internato nos estabelecimentos de instrução secundária e nas escolas normais. In: CONGRESSO DA INSTRUÇÃO, 1884. Rio de Janeiro. Atas e pareceres... Rio de Janeiro: Typographia Nacional, 1884.

MAYA, José da Silva. Relatório do presidente da Província do Maranhão em 28 de outubro de 1870. São Luiz do Maranhão: Typ. de José Mathias, 1871, p. 8.

MOACY, Primitivo. A instrução e as províncias: subsídios para a história de educação no Brasil (1834-1889). São Paulo: Companhia Editora Nacional, 1939, p. 255.

NUNES, Maria Thetis. Ensino secundário e sociedade brasileira. São Cristóvão: UFS, 1999.

NUNES, Maria Thetis. Sergipe Provincial II (1840-1889). Rio de Janeiro: Tempo Brasileiro, 2006.

PENNA, Herculano Ferreira. Fala do presidente da Província da Bahia à Assembléia Legislativa em 10 de abril de 1860. Bahia: Typ. de Antonio Olavo da França Guerra, 1860.

PEREIRA, Lafayette Rodrigues. Relatório do presidente da Província do Ceará à Assembléia Legislativa Provincial em $1^{\circ}$ de outubro de 1864. [n.p.] Typ. Brasileira de Paiva \& Comp., 1864.

POMPÉIA, Raul. O Ateneu. São Paulo: Ática, 2001.

REBELLO, Guilherme Pereira. Relatório do Inspetor Geral das Aulas em 31 de janeiro de 1861. (Anexo) In: ALVES JUNIOR, Thomaz. Relatório do presidente da Província de Sergipe à Assembléia Provincial em 4 de março de 1861. Aracaju: Typographia Provincial de Sergipe, 1861.

REGULAMENTO. Correio Sergipense. Aracaju, p. 2, 2 set. 1854.

RELATÓRIO DO PRESIDENTE DA PROVÍNCIA DO PIAUÍ DE 1852. In: MOACY, Primitivo. A instrução e as Províncias. Subsídios para a história de Educação no Brasil (1834-1889). São Paulo: Companhia Editora Nacional, 1939.

REVISTA DO INSTITUTO HISTÓRICO E GEOGRAFICO DE SERGIPE. Diário do Imperador D. Pedro II na sua visita a Sergipe em 1860. Aracaju: Regina, n. 26, 19611965, p. 68-76. 
SARAIVA, José Antonio. Fala do presidente da Província de Alagoas em 20 de fevereiro de 1854. Recife: Typ. de Santos \& Companhia, 1854.

SERGIPE. Resolução n. 575, de 13 de julho de 1859.

SILVA, José Antonio de Oliveira da. Relatório do presidente da Província de Sergipe em 14 de julho de 1853. São Christovão: Typographia Provincial de Sergipe, 1853.

JOAQUIM TAVARES DA CONCEIÇÃO é professor na Universidade Federal de Sergipe, doutor em História e mestre em Educação.

Endereço: Rua Reginaldo Passos Pina, 399 - 49040-720 - Aracaju - SE - Brasil.

E-mail: jtc@ufs.br.

Recebido em 23 de agosto de 2014.

Aceito em 29 de novembro de 2015. 